\title{
Drinking: Discriminative conditioning in the rat*
}

\author{
MARTIN E. P. SELIGMAN, SUSAN BRAVMAN, and ROBERT RADFORD \\ Cornell University, Ithaca, N.Y. 14850
}

The Pavlovian conditioning of drinking in rats was demonstrated and shown to be under stimulus control. Distinctive conditioned stimuli previously paired with injections of thirst-inducing hypertonic saline-procaine enhanced drinking over stimuli paired with no injections. Extinction, reconditioning, and reextinction also were demonstrated.

The Pavlovian conditioning of aversive drives is a well-established fact. Just how general the conditioning of motivators is, however, is a matter of dispute, because the evidence for the conditioning of appetitive motivations is limited.

When a stimulus (CS) is paired with an aversive motivator such as pain induced by electric shock, the CS readily takes on some of the properties of the US. It is not clear that "appetitive" motivations such as hunger and thirst can be conditioned. Attempts to enhance eating by conditioning (Calvin, Bicknell, \& Sperling, 1953; Siegel \& MacDonnell, 1954; Wright, 1965; Wike, Cour, \& Mellgren, 1967; Cravens \& Renner, 1969) have met with mixed success, and no attempt to classically condition drinking (Andersson \& Larsson, 1956; Novin \& Miller, 1962) has succeeded. Indeed, Cofer \& Appley (1964, p. 582) concluded that "there is currently no evidence for the acquisition of drives on the basis of appetitional needs." This paper presents such evidence: Water drinking is conditioned and shown to be under the control of explicit external cues.

We have recently seen the following phenomenon in our laboratory (Seligman, Ives, Ames, \& Mineka, in press): When an adult rat that is $1-\mathrm{h}$ water deprived is placed in a white box, it drinks about $3 \mathrm{ml}$ of water in $45 \mathrm{~min}$. If the rat is then given 10 daily thirst-inducing injections of $2 \mathrm{ml}$ of hypertonic (15\%) saline-2\% procaine solution, and placed in the white box for $45 \mathrm{~min}$ following each injection, it drinks about $15 \mathrm{ml}$ if water is available. Following these 10 conditioning sessions, it drinks about $6.5 \mathrm{ml}$ of water when it is placed back in the white box, 1 -h deprived but given no injections. This is a robust effect, and the enhanced drinking shows no signs of diminution or extinction, even after 55 sessions of exposure to the white box without the injections. Control rats given injections of isotonic saline and then placed in the box show no enhanced drinking.

Is this enhanced drinking the result of

*Supported by Grant MH 16546 of the National Institutes of Health to M. Seligman. learning or is it merely a permanent physiological change in water intake brought about by the hypertonic procaine injections? At first glance, the phenomenon looks like the Pavlovian conditioning of drinking, since it falls into the defining paradigm: CS (white box, 1-h deprivation) is paired with a US (injection of thirst-inducing saline) that elicits a UR (drinking if water is available). Eventually, the CS alone enhances drinking (CR). The failure of the CR to extinguish when the CS is presented alone, however, makes some permanent physiological change a plausible explanation, since extinction is universally observed in Pavlovian conditioning. The present study demonstrates that enhanced drinking occurs only in the presence of those external cues that have been explicitly paired with injections and does not occur to cues that have been explicitly paired with no injections. Such acquisition of stimulus control is commonly taken as establishing that the phenomenon in question is learning.

\section{SUBJECTS AND PROCEDURE}

Fourteen male albino rats of the Sprague-Dawley strain, 120 days old at the start of the study, were run daily for 123 consecutive days. The experiment was divided into five parts: baseline, discriminative conditioning, extinction, reconditioning, and reextinction. During the 10 days of baseline, each rat was deprived of water for $1 \mathrm{~h}$ and placed either in a white box or in a black box. On half of the days (randomly chosen), half of the rats were put in the white box and the other half were put in the black box. Water was available in either box and baseline drinking in each box was measured. During the 20 days of conditioning, each rat was again placed, 1-h deprived, in the white box for 10 days and in the black box for 10 days (randomly interspersed). One of the boxes was designated the CSt and one the CS- for each rat. Baseline intake was matched in these two subgroups. No water was available in either of the boxes during the 20 conditioning days. Fifteen minutes before being placed in the CS+, the rat was given a subcutaneous injection of $1 / 2 \mathrm{cc}$ of
$2 \%$ procaine followed by a $2 \mathrm{cc}$ injection of hypertonic (15\%) saline. (These injections cause a normal rat to drink about $15 \mathrm{ml}$ of water in the next hour.) No injections were given before the rat was placed in the $\mathrm{CS}-$. Thus, each rat was exposed to one box consistently paired with the rapid induction of thirst and the other box paired with nothing. During the 64 days of extinction, each rat was placed daily into one of the two boxes (randomly interspersed) after $1-\mathrm{h}$ water deprivation. No injections were given and drinking was measured in the boxes. Following extinction, reconditioning was given over 10 days. Injections were given before $S$ was placed in the CSt on half of the days. On the other half of the days, $S$ was placed in the CS- with no injections given. After reconditioning, reextinction occurred as described above for extinction and continued for 24 days.

Water was always available in the home cage, except for the $1 \mathrm{~h}$ before each session. RESULTS

As can be seen in Fig. 1, conditioned drinking was brought under stimulus control. Ss drank more in the CSt than they had during baseline (Extinction Blocks 1-7, 9, 10, 11 vs baseline; all $\mathrm{p}<.029$, sign test), and more in the CS+ than they did in the CS- during the early part of extinction (CS+ vs CS- on Extinction Blocks 2-5, all $p<.05$, Mann-Whitney $U$ test). Ss' drinking during the CS- was not significantly greater than baseline intake during early extinction except on Block 1 of extinction ( $p<.006$, sign test). The pattern of extinction was noteworthy: Ss gradually drank more during the CS- (Extinction Block 6 vs Extinction Blocks 2, 3, 5: all $\mathrm{p}<.029$ ), until $\mathrm{CS}+$ and $\mathrm{CS}-$ did not differ, and then both CS+ and CSgradually drank less and were not significantly different from each other or from baseline at the end of extinction. After reconditioning, Ss again drank more during the $\mathrm{CS}+$ than they had during baseline (Blocks 18, 19, 20 vs baseline, all $\mathrm{p}<.006$, sign test) and they drank more during the $\mathrm{CS}+$ than during $\mathrm{CS}-$ (Blocks 17-21, all $\mathrm{p}<.05$, Mann-Whitney U tests). The drinking in CS+ gradually declined to the level of drinking in the CS(Extinction Block 22 vs $20, \mathrm{p}<.005$, sign test). No systematic changes in homecage drinking were observed during extinction or reextinction.

\section{DISCUSSION}

Drinking caused by thirst-inducing hypertonic saline-procaine injections can be conditioned and brought under the explicit control of external cues. Discriminatively conditioned drinking gradually extinguished when each rat was 
Fig. 1. Mean milliliters of water drunk in each test cage for the 5 days of baseline (B), the 16 blocks of 2 days of extinction, and the 6 blocks of 2 days of reextinction (Blocks 17-22). CS+ is the box in which rats received hypertonic injections, $\mathrm{CS}-$ is the no-injection box. Initial conditioning took place on the 20 days between $B$ and 1 , reconditioning on the 10 days between Blocks 16 and 17.

repeatedly exposed to both the CSt and CS-, unreinforced. In contrast, when no explicit $\mathrm{CS}-$ is used during conditioning, enhanced drinking shows no sign of extinction (Seligman et al, in press). While explanations of this difference remain speculative, the discriminative conditioning reported here makes it apparent that enhanced drinking does not result from some permanent physiological change but rather from learning.

We have clearly conditioned drinking, but can we conclude that we have provided clear evidence for the conditioning of an appetitive drive? Not necessarily. While it is possible that the external cues have taken on the properties of inducing thirst, it is also possible that enhanced drinking is stress-mediated. Observation of the rats indicated that injections of hypertonic-procaine and their aftereffects were aversive; the rats resisted injection and occasionally developed sores at the sites of injection. Some evidence (Amsel \& Maltzman, 1950) suggests that stress induced by electric shock enhances drinking. Thus enhanced drinking might result from the differential conditioning of stress or "poisoning" to external cues and the conditioned stress might differentially enhance drinking. Finally, it seems worth

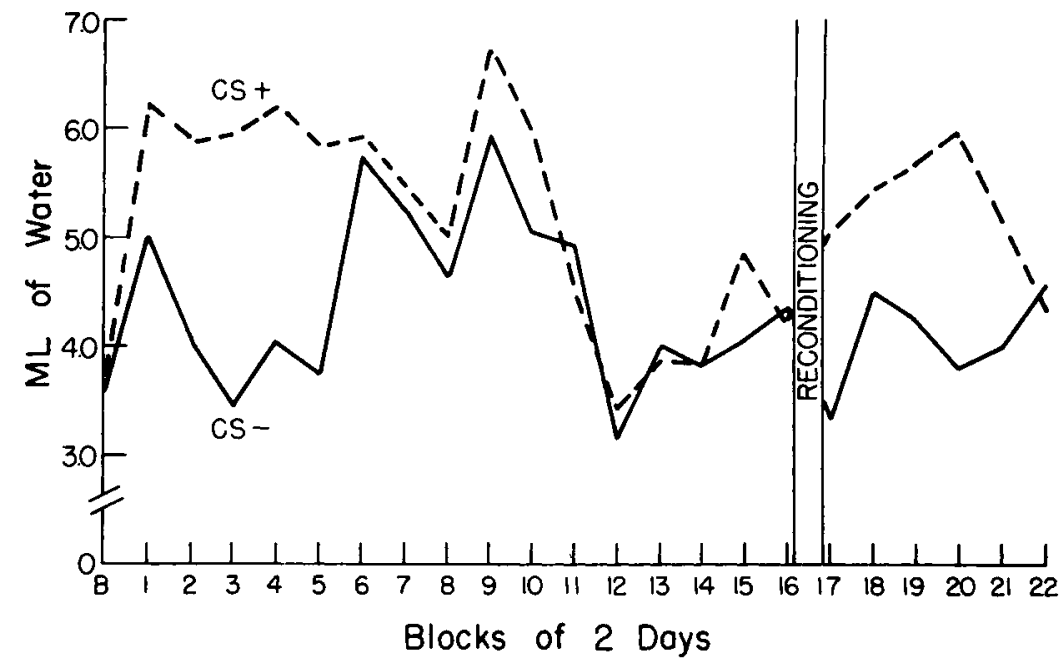

noting the parallel between the conditioning of drinking, and the intriguing findings of Schacter et al (1968), in which eating in obese humans appears to be under the control of external cues. The difficulty we have encountered in extinguishing conditioned drinking suggests that this paradigm might be useful for understanding the stimulus control of eating in obese humans.

\section{REFERENCES}

AMSEL, A., \& MALTZMAN, I. The effect upon generalized drive strength of emotionality as inferred from the level of consummatory response. Journal of Experimental Psychology, 1950, 40, 563-569.

ANDERSSON, B., \& LARSSON, S. An attempt to condition hypothalamic polydipsia. Acta Physiologica Scandanavica, 1956, 36, 377-382. CALVIN, J. S., BICKNELL, E., \& SPERLING, D. S. Establishment of a conditioned drive based upon the hunger drive. Joumal of Comparative \& Physiological Psychology, 1953, 46, 173-175.
COFER, C. N., \& APPLEY, M. H. Motivation: Theory and research. New York: Wiley, 1964. CRAVENS, R. W.. \& RENNER, E. Conditioned hunger. Journal of Experimental Psychology, $81,2,312-316$.

NOVIN, D., \& MILLER, N. E. Failure to condition thirst induced by feeding dry food to hungry rats. Journal of Comparative \& Physiological Psychology, 1962, 55, 373-374.

SCHACTER, S. Obesity and eating. Science, $1968,161,751-756$.

SELIGMAN, M. E. P., IVES, C. E., AMES, H., \& MINEKA, S. Failure to extinguish conditioned drinking: Avoidance, preparedness, or functional autonomy? Journal of Comparative $\&$ Physiological Psychology, in press.

SIEGEL, P. S., \& MacDONNELL, M. F. A repetition of the Calvin-Bicknell-Sperling study of conditioned drive. Joumal of Comparative \& Physiological Psychology, 1954, 47, 250-252.

WIKE, E. L., COUR, C., \& MELLGREN, R. L. Establishment of a learned drive with hunger. Psychological Reports, 1967, 20, 143-145.

WRIGHT, J. H. Test for a learned drive based on the hunger drive. Journal of Experimental Psychology, 1965, 70, 580-584. 